\title{
Receptor $\mathbf{G}$ protein coupling and the cytoskeleton Christoforos Charalambous, Jürgen Zezula and Michael Freissmuth*
}

\author{
Address: Institute of Pharmacology, Center for Biomolecular Medicine and Pharmacology, Medical University of Vienna, Austria \\ Email: Michael Freissmuth* - michael.freissmuth@meduniwien.ac.at \\ * Corresponding author
}

from I 3th Scientific Symposium of the Austrian Pharmacological Society (APHAR). Joint Meeting with the Austrian Society of Toxicology (ASTOX) and the Hungarian Society for Experimental and Clinical Pharmacology (MFT)

Vienna, Austria. 22-24 November 2007

Published: 14 November 2007

BMC Pharmacology 2007, 7(Suppl 2):A76 doi:10.1 I86/I47|-2210-7-S2-A76

This abstract is available from: http://www.biomedcentral.com/I47I-2210/7/S2/A76

(c) 2007 Charalambous et al; licensee BioMed Central Ltd.

The $A_{2 A}$ adenosine receptor is a prototypical $G_{s}$ proteincoupled receptor; it has been proposed as a drug target in the treatment of Parkinson's disease, because there is a mutual antagonism between $\mathrm{D}_{2}$ dopamine and $\mathrm{A}_{2 \mathrm{~A}}$ receptors in striatal neurons. Because of their ability to stimulate endothelial cell proliferation, $\mathrm{A}_{2 \mathrm{~A}}$ agonists are in clinical development for diabetic ulcers. Several modes of coupling have been proposed to account for the interaction of receptor and G proteins; these have been termed precoupling, restricted collision coupling etc. Here, we investigated the mode of coupling of the $\mathrm{A}_{2 \mathrm{~A}}$ receptor by visualizing agonist-induced changes in mobility of the YFP-tagged receptor by FRAP (fluorescence recovery after photobleaching) microscopy. Agonist stimulation did not affect the mobility of the $A_{2 A}$ receptor; in contrast, agonist challenge induced a decrease in the mobility of the $\mathrm{D}_{2}$ receptor. When coexpressed in the same cell, the $\mathrm{A}_{2 \mathrm{~A}}$ receptor precluded the agonist-induced change in $D_{2}$ receptor mobility. Thus, the $A_{2 A}$ receptor does not only undergo restricted collision coupling but it also restricts the mobility of the $\mathrm{D}_{2}$ receptor. Restricted mobility is not due to tethering to the actin cytoskeleton but is, in part, related to the cholesterol content of the membrane. Depletion of cholesterol increases receptor mobility, but blunts activation of adenylyl cyclase. We conclude that signalling of the $\mathrm{A}_{2 \mathrm{~A}}$ receptor takes place in cholesterolrich domains of the membrane. 